\title{
The Jacobsen Epoxidation
}

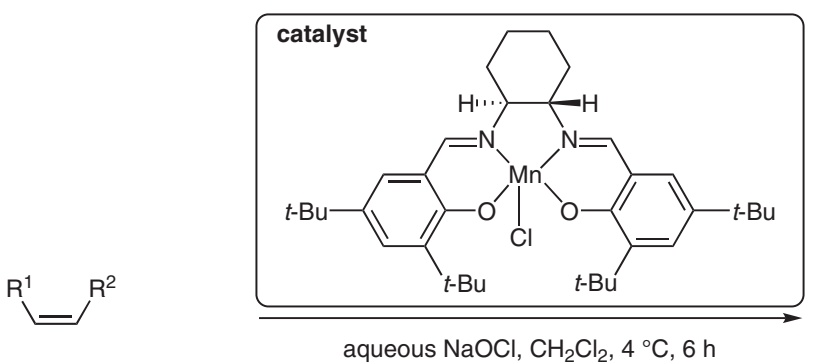

$0.25 \mathrm{mmol}$ scale

Reported examples:

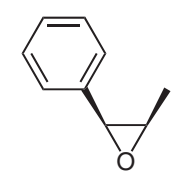

$84 \%$ yield, $92 \%$ ee $4 \mathrm{~mol} \%$ of catalyst required

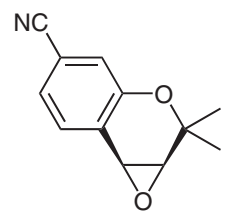

$96 \%$ yield, $97 \%$ ee $3 \mathrm{~mol} \%$ of catalyst required

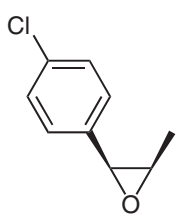

$67 \%$ yield, $92 \%$ ee $4 \mathrm{~mol} \%$ of catalyst required

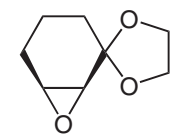

$84 \%$ yield, $92 \%$ ee $15 \mathrm{~mol} \%$ of catalyst required

\section{Category}

Metals in Synthesis

\section{Key words}

alkenes

manganese catalysis

enantioselective

epoxidation

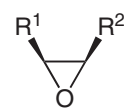

Significance: Although manganese-catalyzed enantioselective epoxidation of nonactivated alkenes had been previously described by Jacobsen (J. Am. Chem. Soc. 1990, 112, 2801) and Katsuki (Tetrahedron: Asymmetry 1991, 2, 481), this report was the first general and highly enantioselective method to achieve this transformation. When compared to the Sharpless epoxidation, this method does not require allylic alcohols and works best with cisalkenes.
Comment: Jacobsen found that by optimizing the size of the salen ligand, the approach of the olefin towards the metal center could be controlled. Thus, the bulky tert-butyl groups on the aromatic rings of the salen ligand limit the chance of competing approaches to the substrate. 